\title{
Ausiàs March o la tragedia del corazón
}

\author{
Fernando Sánchez Alonso \\ U. C.M.
}

A Piedad M.

Y al grande catalán, de amor maestro, Ausiàs March, que en su verso pudo tanto, que enriqueció su pluma el nombre nuestro con su fuerte y sabroso y dulce llanto.

Juan Boscán, Octava Rima

\section{AMANECE EL AMOR}

El amor habría de aguardar hasta el siglo XII para convertirse en verdadero protagonista del sentimiento, sobre todo si tenemos en cuenta que el mundo antiguo careció de un conjunto de prácticas, ideas y conductas amorosas reconocidas y observadas por una comunidad. Platón establecía en El Banquete la naturaleza, el origen y los tipos de amor, alegando por boca de Sócrates que el auténtico debía culminar en lo espiritual. De este modo el hombre debía trascender el amor físico y conducir su alma a la contemplación de la Belleza eterna y divina, que residía en el mundo eidético ${ }^{1}$. Se establecía así una lucha entre

\footnotetext{
' Diotima, personaje platónico, dice: “(...) empezar por las cosas bellas de este mundo teniendo como fin esa belleza en cuestión y, valiéndose de ellas como de escalas, ir ascendiendo constantemente, yendo de un solo cuerpo a dos y de dos a todos los cuerpos bellos, y de los cuerpos bellos a las normas bellas de conducta, y de las normas de conducta a las bellas ciencias, hasta terminar, partiendo de éstas, en esa ciencia de antes, que no es ciencia de otra cosa sino de la belleza absoluta, y llegar a conocer por último lo que es la belleza en sî" (Banq, 211c). Esta idea la repetirá Plotino andando los siglos: "(...) la belleza corpórea se origina de la participación en una razón que viene de los dioses (...), imagen y sombra en huida, que viene a la materia para ordenarla y embellecer y llenarnos a la vez de admiración" (Enéadas, I, 6, 2-3).
} 
cuerpo y alma, entre la pasión sexual y el agápe, término que luego empleará la Patrística para definir el afecto espiritual, y en la que el alma debía resultar vencedora. Es cierto que Platón pudo crear un código amoroso, pero se lo impidió el hecho de reducir el amor a lo contemplativo, a un erotismo que excluía a la mujer.

En Aristóteles se aprecian ecos de la teoría del Fedro platónico (centrado en el impulso sublime del alma amante), cuando dice que la divinidad mueve el universo a través del amor que inspira lo creado. Esta teoría del amor como copula mundi que armoniza lo superior y lo inferior, que rige el movimiento de las esferas y empuja al hombre a unirse con Dios, la compartirán Dionisio Aeropagita, Maimónides o la Escolástica y, andando el tiempo, constituirá una de las ideas básicas de los tratados renacentistas de amor, como se aprecia en los de León Hebreo (Diálogos de amor), Giordano Bruno (Los heroicos furores) o Ficino (De amore).

Así, pues, ahora se comprende la importancia que el amor tuvo en el siglo XII, concretamente en Provenza, Mediodía de la antigua Galia, cuando insinué que marcaba una revolución en la forma de entender el sentimiento amoroso. A diferencia de la Antigüedad, el amor va a dejar de ser algo propio, circunscrito a la conciencia individual (recuérdense los poemas de Teócrito, de Safo, de Propercio o de Catulo), para convertirse en la ética y estética de un grupo social.

¿En que se cifra ese cambio? Por de pronto, en la distinta condición de la mujer, que se negará a seguir representando el papel que se le adjudicó durante casi toda la Edad Media, y que podría resumirse brevemente en tres palabras: sumisión al varón ${ }^{2}$. Esta emancipación viene alentada no sólo por la prosperidad económica y un incipiente capitalismo, sino también por el desarrollo de nuevas formas de piedad exclusivamente femeninas a través de las comunidades beguinas, y por el no menos importante fervor a la Virgen que florece en esos años. No hay que olvidarse tampoco de la apertura que supusieron las Cruzadas. Gracias a éstas los europeos fecundaron su espíritu al acercarse a

\footnotetext{
2 San Agustín, cuya influencia sobre el pensamiento medieval y aun en el actual fue determinante, muestra en su obra la misma opinión que San Pablo (Corintios, XI, 7-9, 11-12) con respecto a la mujer. En el libro XIII, cap. 32 de sus Confesiones se lee: "Y de igual modo como en el alma del hombre hay de un lado una reflexión que manda y de otro una obediencia que se somete; de igual modo la mujer, creada físicamente para el hombre, tiene como él una inteligencia razonable, pero en virtud de su sexo permanece sometida al sexo masculino." San Agustín, Op. cit., prólogo y traducción de Agustín de Escaláns, Barcelona, 1986, pág. 331. Más allá llega Santo Tomás de Aquino cuando indica en la Summa Theologica que: "la mujer es algo deficiente y accidental, porque la virtud activa, que se encuentra en el semen del marido, tiende a reproducir su semejante perfecto según el sexo masculino. Pero cuando se engendra una mujer es a causa de la debilidad de la virtud activa, o a causa de una indisposición cualquiera de la materia, o incluso a causa de alguna transmutación accidental." Este juicio sigue aún vigente en el siglo XV. Alfonso de Palencia, en su Universal vocabulario (Sevilla, 1490), define así a la mujer. "Muger: Mulier que es muger toma nombre de molleza o blandeza assi como vir que es varón tomó nombre de virtud: esto por diferenciar el sexo: ca ombre es vocablo que abraça assi al varón como a la muger." Op. cit., ed. de John M. Mill, Madrid, RAE, 1957. Y podríamos seguir multiplicando ejemplos.
} 
unas costumbres diferentes de las suyas y a una cultura que les redescubrió a Aristóteles y les ofreció la muy desarrollada y sistematizada filosofía árabe.

Sin estos cambios, sin esta nueva situación de la mujer, la literatura provenzal del siglo XII no sería explicable. Dicha evolución de la condición femenina afectó sobre todo a las mujeres de la nobleza. Los poetas se servirán, para cantarlas, de un vocabulario que hibrida términos del lenguaje jurídico, de la exégesis bíblica y de la lírica árabe. Acaba de nacer el "amor cortés" o fin'amors ${ }^{3}$. Pero antes de mostrar en qué consiste, creo que sería conveniente aclarar que el epíteto "cortés" no tenía el significado de hoy en día le atribuimos: indicaba sencillamente la oposición entre villa y corte. Si Virgilio había alabado la clase de vida que ofrecía la aldea, ahora asistiremos a su rechazo por su forma grosera de sentir el amor, tan distinta a la desarrollada en el ámbito cortesano, donde residían los trovadores ${ }^{4}$.

En efecto, el trovador estaba vinculado a la corte como vasallo, e incluso en el siglo XIII a veces como una especie de funcionario del tipo de poeta áulico. Sus obligaciones, por decirlo de alguna manera, consistían en celebrar la hermosura, el juicio, la bondad y la nobleza de la dama. Fácilmente se comprende que a menudo este afecto hubiese de ser fingido y se convirtiese en un amor depurado, en una fin'amors. En el siglo XVI Garcilaso, en el soneto "Boscán, vengado estáis con mengua mía", corregirá los reproches hechos al amigo barcelonés, a quien había acusado de escribir poesía amorosa sin un sentimiento auténtico que la justificase, y se lamentará de no haber seguido su ejemplo, pues ahora que está enamorado sus palabras no saben decir de amor, debido a que no se ejercitó en fingirlo, en escribir sobre él. Juan Alfonso de Baena reclamaba al poeta muy largas lecturas y saberes cortesanos "e otrosy que sea amador, e que siempre se preçie e se finja de ser enamorado"s. León Hebreo dirá que la teoría amorosa debe preceder a la práctica.

\footnotetext{
${ }^{3}$ Cuando los trovadores hablan del "amour courtois" suelen emplear los sintagmas "bon'amors" y "verai' amors", entre otros. Sin embargo, el más utilizado y el que ha hecho fortuna es fin'amors, que significa "amor fino, refinado". Indicar por último que amor es voz femenina en provenzal.

${ }^{4}$ En una farsa de Lucas Fernández (1474-1541), cuyos personajes protagonistas son un pastor y una dama, aquél la requiebra valiéndose del vocabulario de la "cortezia", ante lo cual ésta reacciona preguntando: "¿Y hasta acá el amor extiende/ su poder entre pastores?" Farsas y Églogas, ed. de María Josefa Canellada, Madrid, 1973, p. 205. Esta creencia de que los villanos no podían ser objeto del amor cortés procede del siglo XIII. En el tratado de Andrea Capellanus, De arte honesta amandi, se nos explica lo que un hombre cortesano entendía por de amore rusticorum: "Dicimus enim vix congitere posse, quod agricolae in amoris inveniantur curia militari, sed naturaliter sicut equus et mulus ad Veneris opera promoventur, quemadmodum impetus eis naturae demonstrat." Cfr. MARTíN DE RıQUER, Los trovadores (Historia literaria y textos), vol. I, Barcelona, 1983, p. 85. Ciertamente, los que practican este tipo de amor no salen bien parados en el juicio de el Capellán. Tanto es así que debido a la imposibilidad de contener sus impulsos libidinosos, el autor no vacila en equipararlos a las bestias (equus et mulus), lo que no significa que los hombres "corteses" se negasen a satisfacer las exigencias de la sexualidad. Martín de Riquer cita un poema de Guillem de Berguedà donde el poeta confiesa que cierta noche estuvo con una dama que lo hizo botar como una pelota, "per que fay mal cavalgar En bestia c'axi trota" (Cel so qui capol'e dola, 210, 6b; vol. II, p. 138.) Con todo, dicho tratadista, al igual que la erótica árabe, exalta la continencia y elogia los amores castos.

${ }^{5}$ Cancionero de J. A. de Baena, edición de J. M. Azáceta, Madrid, CSIC, 1966, I, p. 5, Prologus Baenensis.
} 
Regresando a nuestro tema, hemos de mencionar que las damas del mediodía de la Galia, de Cataluña y del norte de Italia aceptaron este homenaje de amor y que, por lo general, fue bien tolerado por el marido. Con todo, no era improbable que este afecto pudiera convertirse en amor real y hasta apasionado, aunque, eso sí, debidamente encubierto. La ceremonia del homenaje vasallático en que se basa el amor cortés podía representar actitudes y situaciones sensuales: el contacto de las manos, por ejemplo, y, sobre todo, el beso en la boca. No obstante, la dama se complacía en mostrarse poco accesible amorosamente, una actitud profundamente femenina, pero también propia de un gran señor que vende caros sus favores. Así, pues, el poeta se va a ver precisado a acentuar dos aspectos. Por una parte ha de demostrar que la fin'amors ha acrecentado en él todos los valores y las virtudes de la cortesía, perfección moral y social que intentará conseguir gracias a su empeño en hacerse merecedor del premio de la dama. Y por otra se va a imponer una especie de ascesis que lo conducirá a un estado de enamorado perfecto. Queda de manifiesto, pues, la equiparación de las relaciones amorosas entre hombre y mujer con las mantenidas entre el señor feudal y su vasallo; tanto es así que el trovador no dudará en confesarse vasallo $(\mathrm{om})$ de su dama.

De este modo arranca uno de los hábitos de la literatura cortesana: el proclamar una y otra vez que la dama se ha "adueñado" del corazón del poeta y que su vida deja de ser suya, de pertenecerle. Esta costumbre de reconocerse como servidor la heredaron los provenzales de la España musulmana, donde los emires y grandes señores se habían declarado sirvientes y esclavos de sus amadas, invirtiéndose de esta manera la relación tradicional de los dos sexos. Siguiendo el uso de los poetas de Al Andalus, que designaban a sus mujeres con las expresiones masculinas sayyidi ("mi señor") y mawláya ("mi dueño"), los poetas del amor cortés llamaron a las suyas midons, vocablo que deriva del latín meus dominus. La masculinización del tratamiento tendía a subrayar la alteración de la jerarquía de los sexos, como ya he apuntado, un cambio que seguirá vigente en los poetas catalanes de los siglos XIV y XV.

Pero la mujer a la que canta y por la que se desvive el poeta tenía que ser casada. Se parte del hecho de que los matrimonios entre las clases elevadas no solían ser producto del amor, sino de la conveniencia política o económica. El adulterio adquiere, por consiguiente, un mayor contenido espiritual, pues reposa en un sentimiento genuino, que se perfecciona y pone a prueba en su clandestinidad. Para evitar los problemas que pudiera traerle la intransigencia de los celos, el trovador se imponía cierta cautela en sus relaciones con la dama, a fin de no despertar las sospechas del marido o gilós ("celoso"). De ahí que el poeta determine silenciar el nombre de ésta en sus poemas. No obstante, se va a valer de otro falso, o incluso de una palabra o varias en las que acostumbra resumir las cualidades físicas o morales de la amada, para hablar de ella. Este pseudónimo, que por lo general aparece al final de las tornadas a modo de envío, es lo que se conoce como senhal, distintivo que encubría el nombre de la dama y salvaguardaba el secreto amoroso. 
Aun faltarían por examinar otros muchos aspectos del amor cortés: su posible vínculo con la herejía cátara, la condena de la Iglesia debido a su desprecio por el matrimonio, los cuatro grados que debía recorrer el amante hasta la posesión física de la dama ( $\mathrm{fach}$ ), los términos empleados para referirse a los estados de ánimo del amante, etc. Sin embargo, considero que con lo dicho hasta ahora basta para entender el fondo trovadoresco que subyace en la poesía de Ausiàs March, como veremos más adelante.

\section{AUTENTICIDAD DEL AMOR EN AUSIÀS MARCH}

Comenzaba estas páginas con una cita de Boscán, para quien Ausiàs merecía el tan subido dictado de "maestro de amor". En realidad, esto no debe sorprendernos demasiado, pues era un título concedido frecuentemente a los poetas. Bastará con recordar la gran estima en que Petrarca tuvo al provenzal Arnaut Daniel - a quien Dante había destinado al Purgatorio (XXVI, 142, cerca de Guittone d'Arezzo) - como lo declaran estos versos del Triumphus Cupidinis, para comprobarlo:

fra tutti il primo Arnaldo Daniello, gran maestro d'amor, ch'a la sua terra ancor fa onor col suo dir strano e bello.

Con todo, de las palabras de Boscán se deduce que la obra de March va a ser de temática amorosa, si exceptuamos algunos poemas de corte didáctico, filosófico o religioso que no forman una unidad aparte en su cancionero, sino que conviven con la poesía de amor, a la que apoyan conceptualmente ${ }^{6}$. Ahora bien, el título que le concedió Boscán a su colega valenciano pudo deberse tanto a la lectura de March como al hecho de que éste observó cierta costumbre de los trovadores, quienes solían aplicarse adjetivos tan empinados que ni siquiera los más excelsos y positivos de la lengua servían para abarcar la compleja belleza de su señora, para calificar su perseverancia en el amor o para acentuar debidamente sus cuitas cuando obtenían los desdenes de la amada. Pero Ausiàs March superó con mucho la vanidad de sus predecesores. Se proclamó machaconamente el mejor amador de todos los tiempos, algo que debe considerarse tanto una actitud literaria como una creencia no muy alejada de la verdad, si se tienen en cuenta el carácter altanero del poeta, su vida de gran

\footnotetext{
${ }^{6}$ Poesía amorosa muy seria, además. Ausiàs March no tolera que se burlen del amor o que hablen de él a chacota. A este respecto se manifiesta tajante: "D'amor no sab qui's cuyda ser ginyos" (CXXIII, 65), es decir, "de amor no sabe quien se preocupa de ser ingenioso", porque la filosofía no es cosa de ingenios, y él pretende un intelletto d'amore, una filosofía del amor.
} 
señor feudal y sus campañas militares al lado de Alfonso $\mathrm{V}$, combinando así la sapientia et fortitudo, la unión entre armas y letras que tan cara sería a Garcilaso, a Diego Hurtado de Mendoza o a Francisco de Aldana por ejemplo ${ }^{7}$. Se entiende ahora que el valenciano afirme con petulancia: "conmigo no se puede comparar hombre viviente." (LXII, v. 9) ${ }^{8}$, y que esa misma vanidad la traslade al terreno amoroso. Sin tapujos nos confiesa que las reglas y artes del amor las ha enseñado a los amadores necesitados de saber:

per mon sentir regles n'he dat e art

als amadors freturans de saber

(LXXI, vv. 27-28)

Su narcisismo llega a desbordarse cuando ordena que no sólo deben callar aquellos que han hablado antes del amor, sino que, además, han de destruirse los textos de los antiguos sobre el tema, pues pecan de ignorancia y superficialidad en comparación con sus conocimientos. Niega, por otra parte, que alguien pueda estar enamorado: únicamente su alma padece las inclemencias del deseo sin tener esperanzas de aliviarlo (XXII, 1-5). Muy seguro de sí, se ofrece como modelo, y del mismo modo que hará don Quijote más tarde, será espejo de leales amadores:

Faent bé a molts a la mort me acús, car seré spill de leals amadors prenint remey a totes llurs dolors, car envers mi tota dolor és jus.

(XXII, vv. 33-36)

Estas "fanfarronadas" consienten otra interpretación, sin embargo. Sabido es el deseo de fama del hombre de la Alta Edad Media, el afán de que su nombre se eleve por encima de su tiempo y planee las centurias venideras. Así, pues, Ausiàs March ligará el suyo al amor, de la misma forma que el poeta gallego Macías el Enamorado o Garci Sánchez de Badajoz, que, según es fama, murió loco de amor. Para encumbrarse a la inmortalidad, uno de los caminos posibles, amén del de las armas, era el de la palabra poética, ya que la palabra vence la "fuga temporum" sin dejarse roer por la lluvia y el aire que destruyen los monumentos, como expresó Horacio y conjugará nuestro poeta cuando sugiera que no se muere del todo si alguien comparte nuestras palabras (XXXIX). Máximo Valerio había mencionado en su Factorum et dictorum memorabilium libri novem el poder de la palabra para defender a los hombres del olvido. Esta opinión la leemos también en Juan de Mena:

\footnotetext{
${ }^{7}$ Gil Polo, en su "Canto de Turia" de La Diana enamorada (Valencia, 1564) ensalza a Ausiàs March como poeta y soldado: "Ya veo al gran varón que celebrado / será con clara fama en toda parte,/ que en verso al roxo Apolo está igualado / y en armas está al par del fiero Marte."

${ }^{8}$ Desde ahora citaré por la edición de Rafael. Ferreres: Ausiàs March, Obra poética completa, Madrid, 1979, 2 vols. De R. Ferreres son también las traducciones, a menos que se indique lo contrario.
} 
levante la Fama su boz ineffable, por que los fechos que son al presente vayan de gente sabidos en gente:

olvido non prive lo que es memorable. (copla III, vv. 21-24)

Y en el Prologus Baenensis encontramos: "Ca sy por las escripturas non fuesse, ¿qual sabydurya o qual engeño o memorya de omnes se podrye membrar de todas las cossas passadas?" Por eso Ausiàs, prosiguiendo una práctica que ya se encontraba en Virgilio ${ }^{10}$, y que heredarán los poetas provenzales, circulando después por Berceo, Juan Ruiz o Cervantes, se mencionará a sí mismo en un bello canto donde también nos proporciona un rasgo de su personalidad: la tristeza.

Puix que lo món ne Déu a mi no val

a rellevar la causa d'on só trist,

a mi plau bé la tristor que yo vist:

delit hi sent mentre yo $\cdot \mathrm{m}$ trobe tal.

Així dispost, dolç me sembla l'amarch,

¡tant és en mi enfecionat lo gust!

A temps he cor d'acer, de carn e fust:

yo só aquest que $\cdot \mathrm{m}$ dich Ausiàs March.

$(\mathrm{CXIV}, 81-88)^{11}$

Es esta tristeza la que va a teñir su poesía, que si no se caracteriza por su preciosismo formal, sí destacará por su hondura humana. Como en Proust, su obra traduce una existencia amorosa más rica en análisis psicológicos que en hechos externos. La amada en Ausiàs March es una disculpa no sólo para averiguarse en la inquietud de su vivir, sino también para justificar la trayectoria hacia la soledad de contemplarse a sí mismo. De ahí que alguna vez pueda cubrimos la sospecha de que está menos enamorado de una mujer concreta que del amor. En LXIII declara que lo ha buscado dentro de sí ("e yo qui - l cerch dins mi", vv. 33-34), confirmando de este modo el aserto de Ortega y Gasset: "se ama el amor, y lo amado no es, en rigor, sino un pretexto." Otras veces nos gana la certeza de que el poeta únicamente se ama a sí mismo, anticipándose esta vez a aquel parecer que Mario Equicola expondría en su Libro de natura d'amore (1526): todas las clases de amor son aspectos del amor a uno mismo.

\footnotetext{
9 Laberinto de Fortuna, edición de Miguel Ángel Pérez Priego, Madrid, 1989, p. 58.

${ }^{11}$ En las Geórgicas, IV, 563 se lee: "Illo Virgilium me tempore dulcis alebat / Parthenope studiis florentem ignobilis oti..." Citado por ERNEST ROBERT CURTIUs, European Literature and the Latin Middle Ages, Nueva York, 1953, cap. XVII.

II "Pues que el mundo ni Dios me valen para quitar la causa por la que estoy triste, a mí me place bien la tristeza que yo visto: siento deleite mientras tal me encuentro. Así dispuesto, dulce me parece lo amargo, ¡tanto está en mí infeccionado el gusto! A la vez tengo el corazón de acero, de carne y de madera: yo soy este que se llama Ausiàs March."
} 
Quisiera ahora recordar que no toda la poesía que se escribía en aquel momento histórico obedecía a las leyes del código provenzal o petrarquista. Abundaba una literatura que aprobaba el goce de los sentidos y consentía los amores carnales, como lo ilustra la tradición que va de Francesco de Barberino al Decamerón de Boccaccio. Es más, algunos poetas pronto arremetieron contra la donna estilnovista: Cecco Angiolieri la opuso a su Becchina, por ejemplo. En el Renacimiento se escribirán diálogos que acentúan esta línea, como la Raffaella, dialogo della bella creanza delle donne, de Piccolomini. Esta tradición realista culminará en el mencionado tratado de Equicola, quien concebía el amor como un sfogo de los sentidos. Así, pues, Ausiàs March concurre en el término medio de estas dos direcciones poéticas, y será de esta contradicción de donde nazca la riqueza de su poesía, una poesía que tiene no poco de autobiográfico. Veámoslo.

Ausiàs contrajo nupcias en dos ocasiones. La primera con doña Isabel Martorell y Monpalau. Cuatro años después, cuando ésta fallece, repite casamiento: doña Juana Escorna y Catellá será su nueva esposa. A estos dos amores cabe añadir alguno más, como lo evidencia la cantidad de hijos ilegítimos habidos con distintas mujeres. Es como si nuestro poeta se hubiera tomado muy en serio aquella afirmación provenzal de Gui d'Ussel, expuesta en su "partimen" con Elias d'Ussel, sobre las ventajas y conveniencias de cortejar a las damas frente a atender a la esposa:

per dompa vai bos pretz enan

e per moillier per hom valor,

e per dompnei de dompna es hom grazitz

e per dompne de moiller escarnitz ${ }^{12}$.

Se puede afirmar, pues, que nuestro poeta conocía a fondo el amor y sus contradicciones, todo lo cual se manifiesta en su obra. No se olvida de nada: los desvelos de la carne, la culpa, la desazón por no poderse acercar al amor celeste. Su ánimo vacila entre la exaltación más encumbrada y la disforia más afligida. $\mathrm{Al}$ igual que Catulo ${ }^{13}$, se debate entre el amor y el odio con respecto a la amada:

air e am molt e mescladament

(LXX, v. 38)

entre Amor ab Oy desacordant:

cascú d'aquests en mi és tan poxant,

que mon saber no $\cdot$ hy coneix diferença.

(LII, vv. 30-32)

12 Cfr. "Ara'm digatz vostre semblan", III, en MARTín DE Riquer, Los trovadores. (Historia literaria y textos), Barcelona, 1983, p. 1014. Sospecho que esta dilatada experiencia amorosa parece querer contradecir aquel testimonio de Ortega y Gasset, quien afirmaba que los que escribían sobre el amor eran los que menos lo habían sentido.

${ }_{13}$ Catulo, en un tono de angustiada pasión, le dice a Lesbia: "Odio y amo. Tal vez me preguntes por qué lo hago. No lo sé, pero lo siento así y sufro." (LXXXV) Carvlo, Poesía, introducción, traducción y notas de Joan Petit, Barcelona, 1990, p. 115. 
El conflicto de Ausiàs March es tanto de índole psicológica como metafísica. Para él el amor no es sólo una forma de vida como para los trovadores; es eso y mucho más: es una forma de conocimiento, como vemos en XVIII, vv. 49-54.
Als naturals no par que fer-se pusquen molts dels secrets que la deytat s'estoja, que revelats són stats a molts martres, no tan suptils com los ignorants y aptes. Axí primors Amors a mi revela, tals que $\cdot$ ls sabents no basten a comprendre ${ }^{14}$.

Más de un siglo después, Giordano Bruno llegará a la misma conclusión en De Vinculis in genere: "Omnis afectus valde practica est cognitio", el conocimiento se alcanza con la práctica constante de los sentimientos, dirá al definir el amor. Bruno considera que el objeto es conocido en una situación afectiva, de manera que se identifican sentimiento y conocimiento. El amor (vinculorum vinculum) hace que el sujeto salga de sí mismo para entrar en contacto activo con el mundo.

Estas ansias de conocimiento de Ausiàs revelan la voz de un hombre hablando de sus angustias y felicidades, de su visión del amor y de la muerte. Pensemos (lo rastreamos ya en los trovadores, en la recomendación de Juan Alfonso de Baena, y lo encontraremos de nuevo en el Prólogo de López Maldonado a su Cancionero y en el soneto aludido de Garcilaso) en lo que una historia amorosa $-\mathrm{y}$ la de Ausiàs lo es- pueda tener de fingimiento, de acuerdo con la sinonimia de poesía y ficción registrada en el Fedón platónico. En ocasiones la creencia en la falsedad de los poetas llegaba hasta tal extremo, que en 1336 Petrarca ha de escribir una carta a Giacomo Colonna, obispo de Lombez, defendiéndose de la acusación de simulador. El prelado discurría que el nombre de la amada era una invención de Petrarca para con ella (Laura) conseguir la laurea, el lauro (laurel) de poeta, es decir, su inmortalidad. La respuesta es una afirmación de la existencia de la amada y de su amor por ella. La carta a Colonna se cierra con una petición: "Hoc saltem oro, ne finxiesse me fingas", no imagines que estoy fingiendo.

Ausiàs March pondrá también las cosas claras sobre la autenticidad de sus sentimientos. Con harta frecuencia arremete contra los trovadores. Los repudia porque cantan el amor sensual (LXXXVII), lo que no quiere decir que él no lo haga alguna vez ${ }^{15}$. Ellos no han dicho la verdad sobre el amor, le participa a

14 "A los humanos no les parece que puedan realizarse muchos de los secretos que guarda la divinidad y que han sido revelados a muchos mártires, no tan sutiles como los sabios y los ignorantes: así Amor me revela sutilezas que los sabios no alcanzan a comprender."

15 "Mon pecat és amar follament" (Mi pecado es amar locamente), XXII, v. 26. O también: "Aquell. amor per qui ma carn s'enclina, / compliment sent dels béns que Venus lliura", LXXXVII, vv. 221-222. 
una de sus amadas, la que disimula el senhal Lir entre carts ("Lirio entre cardos"), pseudónimo de una mujer a la que el poeta cantó en su primera etapa, según opina Martín de Riquer:

Lir entre carts, molts trobadors han dit que.l bé d'Amor és al començament; yo dich qu.està prop del contentament: d'aquell ho dich qui mor, desig finit. (LV, vv. 41-44)

No satisfecho con esto, renuncia de manera explícita y clara al estilo de los trovadores, pues éstos son mendaces y embusteros:

Llexant a part l'estil dels trobadors qui, per escalf, trespassen veritat.

(XXIII, vv. 1-2)

A propósito de este rechazo del quehacer trovadoresco y de la afirmación de la veracidad de sus sentimientos, como ya hiciera Petrarca, Martín de Riquer ${ }^{16}$ indica que en el inventario de los bienes de Ausiàs March figuraba un libro sobre la Gaya Ciencia. Que Ausiàs lo poseyera es algo lógico en alguien interesado por la poesía. Nuestro poeta fue pariente de Jaume March, tan relacionado con el Consistorio de Barcelona y autor del Diccionari de rims. Pero eso no justifica que, cuando el poeta escribe que "ha ojeado el libro de aquel saber que no dura sin amor" (V, vv. 17-20), haya de referirse forzosamente a los libros teóricos de la Gaya Ciencia. Podría aludir, arguye Riquer, a la obra de Ovidio (Ars amandi) o a la de Aristóteles o Santo Tomás cuando hablan de la pasión amorosa, obras que se sabe de cierto que conocía, y a las que luego he de aludir.

Es verdad, con todo, que la poesía de Ausiàs March admite algún tema de raigambre provenzal, y que algunas veces imita pasajes de algún trovador. Sin embargo, el estilo del poeta valenciano es lo más opuesto a la delicadeza, elegancia y armonía que resume la canço provenzal. Para Ausiàs los trovadores fueron un mero trampolín desde el que se lanzó a la aventura de ser él mismo. $\mathrm{Ha}$ acumulado todos los conocimientos poéticos precedentes y ahora es un enano encaramado a los hombros de un gigante, como diría Bernardo de Chartres, pues al saber ajeno ha agregado el suyo propio.

Por otra parte, y para explicar cabalmente el deseo de originalidad del poeta valenciano, hay que tener presente que el Renacimiento está a punto de llamar a las puertas de España ${ }^{1 t}$, con lo que eso supone de afirmación de la

\footnotetext{
${ }^{16}$ Història de la literatura catalana, III, Barcelona, 1984, p. 217.

${ }^{17}$ Manuel de Montol.ju, como conclusión a su libro Ausiàs March (Barcelona, 1959, p. 147) afirma: "(... Ausiàs... no es un trobador retardat, sinó un renaixentista anticipat"). Citado por la introducción de Rafael FerReres a la ed. cit., p. 45. Suscribimos esta opinión.
} 
individualidad, de la personalidad propia. Petrarca pasó de la servidumbre de la imitatio a la libertad de la aemulatio. El autor imitado no era más que un punto de referencia que permitía apreciar la originalidad del poeta. "Pretendo seguir", aseguraba el toscano, "el camino marcado por los maestros, pero no siempre las huellas ajenas; servirme de los escritos de otros no de un modo furtivo y como a escondidas, sino como pidiendo permiso, y, si cabe, prefiero usar los míos; me agrada el parecido, no la igualdad, y aun ese parecido, no servil, debe revelar el ingenio y no la ceguera ni la pobreza del admirador" 18 . Y a Paolo Cortesi, que jamás osaba apartar los ojos de Cicerón, le espoleaba Poliziano: "Me gustaría que por fin te decidieras, como suele decirse, a nadar sin corchos, a valerte de una vez por ti mismo"19. Como desde luego hace Ausiàs March en el poema XCIX. Pocas composiciones de sus predecesores pueden igualársele en sinceridad, pues, como quería Nietzsche, está escrita con sangre. En ella el arrepentimiento por haber cedido a la irracionalidad de la concupiscencia es tan agudo y tan severo, que le llevará al poeta a anhelar una muerte atroz. Aún agonizante, nos dice, su cuerpo debe ser repartido entre los perros, los milanos y los cuervos, y su espíritu deberá residir al lado del de Judas, pues él también ha traicionado a Dios y "a un gran pecado debe corresponder grave pena".

No dec morir solament ab coltell:

mon cors mig mort deu ser viand'als cans;

mon cor, partit entre corbs e millans;

mon espirit tinga lo loc d'aquell

qui volc trair, besant, lo Fill de Déu:

aquest és loc a ell just e degut;

puis ha traït a si, Deu no l'ajut,

e.n gran pecat deu rebre pena greu $^{20}$.

Este desgarramiento entre el entendimiento y el instinto, que sólo busca satisfacer las urgencias del amor ferino, es el que le llevará a proferir un grito de angustia en el que concentra todas sus esperanzas. El recuerdo de Lope de Vega o de Unamuno es inevitable cuando Ausiàs, solo como los muertos, pide a Dios que le ayude a sobrellevar su desventura:

ik "Sum quem priorium semitam, sed non semper aliena vestigia sequi iuvet; sum qui aliorum scriptis non furtim sed precario uti velim in tempore, sed dum liceat, meis malim; sum quem similitudo delectet, non identitas, et similitudo ipsa quoque non nimia, in qua sequacis lux ingeni emineat, non cecitas, non paupertas", Francesco PeTraRCA, Familiarium rerum libri, XXII, II, 20, edición nacional de V. Rossi y U. Bosco, vol. IV, Florencia, 1942, p. 108.

14 ....tum demum velim quod dicitur sine cortice nates atque ipse tibi sis aliquando in consilio...", A. Poliziano, carta a P. Cortesi, en Prosatori latini del Quattrocento, p. 904. Citado por Francisco Rıco, El sueño del humanismo (De Petrarca a Erasmo), Madrid, 1993, p. 42.

21) XCIX, vv. 81-88. A propósito de este poema Martin de RiQuer escribe: "Cal confessar que poques vegades, en un escriptor medieval, es podrien trobar conceptes tan crus i desesperats com aquests." Història de la literatura catalana, III, Barcelona, 1984, p. 195. Pero creo que el respetable estudioso se equivoca al considerar a Ausiàs March como "un escriptor medieval", pues estimo que, si bien no se ha librado completamente del lastre medieval, Ausiàs se aproxima a las prácticas e ideas renacentistas, como muy bien ha demostrado MANUEL DE Montol.Ju. 
Lo meu voler al teu és molt contrari, e.m só.nemich penssant-me amich ésser.

¡Ajuda'm, Deu, puys me veus en tal pressa! (CV, 97-99)

Pero en seguida se disculpa por hablar tan vehementemente, aunque si lo hace, explica, es porque teme el infierno, al que cree encaminarse sin remedio:

Perdona mi si follament te parle.

De passió partexen mes paraules.

Yo sent paor d'infern, al cual faç via.

(CV, 25-27)

Esta sinceridad se acrecienta en los seis cantos de muerte (XCII al XCII), escritos tras la defunción de su segunda esposa. En el primero de ellos Ausiàs March se queja de que los que saben que ha celebrado los amores lujuriosos no entiendan que ahora, con el alma ofrecida en intimidad, hable de un amor honesto. Aquí la dama no es ya la dama inalcanzable de los trovadores, es una mujer de carne y hueso, de quien el poeta cree, además, que se ha condenado por su culpa. Hay unos versos impresionantes en los que el poeta canta a la vida y al amor. Acertó Bataille al definir el erotismo como "la aprobación de la vida hasta en la muerte"21:

$$
\begin{aligned}
& \text { com prop la Mort yo la viu acostar, } \\
& \text { dient plorant: "No vullau mi lexar, } \\
& \text { ¡hajan dolor de la dolor de mi!" } \\
& \text { (XCVII, vv. 18-20) }
\end{aligned}
$$

Acuden después los hermosísimos versos que el poeta inscribirá en el epitafio de la amada. Unos versos que acercan a la memoria los de Propercio, cuando Cintia se le aparece en sueños y, momentos antes de regresar a las aguas del Leteo, le asegura:

nunc te possideant aliae: mox sola tenebo:

mecum eris, et mixtis ossibus ossa teram.

Y Ausiàs:

E lo meu cors, ans que la vida fine, sobre lo seu abraçat vull que jaga:

"Feríls Amor de no curable plaga;

separà'ls Mort: dret és que ella els veïne."

${ }^{2 !}$ Georges Batalle, El erotismo, Barcelona, 1992, p. 28.

22 La amada, “...entre continuos llantos, ya cerca de la muerte, me dijo: “ No me queráis abandonar, tened piedad de mí!" (La traducción es mía). 
Lo jorn del Juí, quan prendrem carn e ossos, mescladament partirem nostres cossos."

(XCII, vv. $245-250)^{23}$

Si se ha seguido hasta aquí, se nota que un elemento fundamental separa a nuestro poeta tanto de los trovadores como de los poetas italianos: su actitud ante la dama. Los provenzales, según se recordará, rendían vasallaje amoroso a la señora. Los estilnovistas opusieron a la midons, que se fundamentaba en el linaje, la donna angelicata, es decir, aquella dama que merece ser cantada no por la nobleza de su sangre, sino por su corazón gentil (cor gentil, "gentil" significaba "noble", y este sintagma encabezará el poema "Amor, ch'al cor gentil ratto s'apprende", de Guinizzelli). La sublimación de la dama es cada vez mayor entre los poetas italianos. Para Dante, Beatrice representará la Teología, que le conducirá hacia Dios; para Petrarca, Laura atesorará la más elevada espiritualidad. En este camino era imposible llegar más arriba. Ausiàs March no lo pretendió. Nuestro poeta consideró simplemente a la dama como mujer, con sus virtudes y defectos, con su firmeza y su debilidad, esto es, un ser capaz de pecar y de hacer pecar al poeta. Se interrumpe, pues, la curva ascendente de la donna, que corría el peligro de perderse más allá de las nubes ("que s'arriscava a perdre's més enllá del núvols", como apostilla Riquer), y la sitúa a ras de tierra, y a ras de tierra la ama o la odia.

\section{AUSIÀS MARCH, ENFERMO DE AMOR}

Algunas páginas atrás copié unos versos del poema CXIV en los que Ausiàs nos confesaba su nombre y se definía como una persona esencialmente triste, a la que ni siquiera Dios le procuraba un alivio, un consuelo. Quizá en otros lugares de su obra cabría recelar de esta tristeza, pues era un topos de la poesía amorosa, y él pretendía ser conocido y reconocido por las generaciones siguientes como prototipo de amador, "mestre d'amor". Sin embargo, no estoy tan seguro de que en esta suerte de autorretrato quisiera mentir. Cervantes nos ofreció el suyo, y en todos los autorretratos, amén de cierta idealización, siempre pervive un fondo de verdad. Téngase presente que problemas de todo tipo acecharon continuamente al poeta, y que por eso mismo no sería aventurado

${ }^{23}$ Los de Propercio, Elegía VII, libro IV, vv. 93-94, dicen así: "Ahora, que otras te posean; pronto te gozaré sola: / serás mío y mezclaré el polvo de tus huesos con el polvo de los míos." Propercio, Elegiae, introducción y notas de Pedro-Luis Cano Alonso, Barcelona, 1984, p. 410. Los de Ausiàs, R. Ferreres los traduce así: "Y mi cuerpo, antes de que la vida acabe, sobre el suyo quiero que yaga. "Los hirió Amor de no curada llaga; los separó la Muerte: razón es que ella los avecine" El Día del Juicio, cuando tomemos carne y huesos, mezcladamente separaremos nuestros cuerpos." Pero hasta entonces estarán juntos. 
suponerle cierto desengaño, cierta desilusión, cierta tristeza. Sea como fuere, será este sustantivo, la tristeza, el que orientará las páginas siguientes. Sirviéndome de las teorías aristotélicas y medievales, me propongo estudiar algunos de los síntomas de la "enfermedad del amor" que irrumpen en la obra del poeta valenciano.

Pero quisiera hacer antes una pausa. Hasta la edición de A. Pagès encabezó el cancionero de Ausiàs March una octava, la XXXIX, con valor de prólogo. Petrarca inicia su Canzoniere con un soneto prólogo de carácter enunciativo, lo que será una práctica en los cancioneros españoles (Hernando de Acuña) o italianos (las Rime de Gaspara Stampa). Si en Ausiàs no aparece la citada octava al principio de la obra, negando así la lectura narrativa que pretendió comunicarle el poeta, se debe a cierta costumbre editora de agrupar las composiciones bien por formas métricas (caso de Garcilaso), bien siguiendo la cronología en que el autor las escribió (caso de Ausiàs March). El hecho de que me haya detenido en explicar esto se debe a que en la octava XXXIX encontramos una declaración de intenciones. Allí se nos dice que su obra va dirigida a los que como él sufren de cuitas amorosas ${ }^{24}$, y se nos anticipa lo que reiterará obstinadamente: está triste. Sus versos "muestran pensamiento turbado" ("mostrans penssa torbada"), ya que fueron escritos por "hom fora seny", por hombre sin juicio. El culpable de ese trastorno es el amor (vv. 6-8). Defiende después la tristeza no sólo como estado permanente del alma, sino también como una forma de vida, ya que de ella resulta el mayor gozo (vv. 26-27):

...e molt pus bell partit

sa tristor gran que tot altre delit ${ }^{25}$.

Termina confesando que está persuadido de que mucha gente lo censura por ensalzar vivir en vida triste ${ }^{26}$.

El poeta se nos ofrece de este modo como ejemplo, como modelo didáctico, y en este sentido sí es pertinente la opinión de Riquer cuando considera a Ausiàs March un poeta medieval. Pero esto nos indica también que el centro de atención no van a ser las sucesivas amadas a las que cantará (Plena de seny, Lir entre cards, Mon darrer bé, Bella ab bon seny), sino el propio poeta averi-

24 Afirma FReLd en El interés del Psicoanálisis para la Estética: "El artista busca, en primer lugar, su propia liberación, y lo consigue comunicando su obra a aquellos que sufren la insatisfacción de iguales deseos. (...) Para el psicoanálisis resulta fácil describir, al lado de la parte manifiesta del goce artístico, otra parte latente, mucho más activa, procedente de las fuentes ocultas de la liberación de los instintos." Citado por Isabel Paraiso, Psicoanálisis de la experiencia literaria, Madrid, 1994, p. 209

${ }^{25}$ Y más específicamente en CXIV, vv. 5-6: "Sens grat seré si jamés la'm despull; / e solament assaig d'ella exir" ("Ingrato seré si me despojo de ella alguna vez o intento salir de ella.")

26 "Ésser me cuyt per moltes gens reprès / puys que tan llou viur-en la vida trista" (vv. 33-34) Hallamos aquí un eco del soneto prólogo de Petrarca: "Mas ¡ay!, que ya conozco y claro veo / que por hablilla anduve entre la gente." Francesco Petrarca, Cancionero. Introducción y notas de Antonio Prieto, Barcelona, 1989 , p. 4. 
guándose, ofreciéndose como modelo. En unos casos será "espejo de leales amadores", según vimos, y en otros alguien cuyos pasos no hay que seguir. Pero en ambos latirá su eterna tristeza y su angustia como en cualquier depresivo, y Ausiàs lo fue. Su pasión se detiene siempre en tristeza:

\section{Ma passió en tristor me deté}

(CXIV, v. 39)

Y es esta tristeza la que le hace saber al poeta que está solo en el mundo, y que el amor no consigue mitigar su soledad, sino que en no pocas ocasiones la agrava, pues lo aparta de Dios, la casa que es segura ("la casa qui m'és certa") ${ }^{27}$, con lo que este término (casa) tiene de simbólico: vuelta a los orígenes, protección, amparo ${ }^{28}$. Será este camino hasta la morada del Padre el que Ausiàs emprenda acompañado por la tristeza. Recuérdese que, como argumento sobresaliente del libro II del Secretum, San Agustín acusa a Francesco de estar dominado por la acidia. Le señala: "Te domina una funesta enfermedad del espíritu: los modernos la han llamado acidia, los antiguos aegritudo" 29 . La acidia que refleja aquí Petrarca, y esto es aplicable a March, está desconectada del sentido griego de apatía. Los moralistas de la época la entendían como una especie de fatiga de obrar bien, una pesadumbre destructora, de raíces tanto físicas como morales. Estamos en la tensión entre el amor mundano y el amor celestial que tanto atormentará a Ausiàs March, porque Dios es el fin donde todos los bienes terminan ("Tu est la fin on totes fins termenen", CV, v. 105) y su "querer no casto" lo aleja de Él. Pero estamos también en la herencia contra el spiritus acediae que en el siglo $\mathrm{V}$ había extendido para el Medievo el libro $X$ del De institutis coenobiorum et de octo principalium vitiorum remediis, del teólogo ascético Juan Casiano, quien llamó a la accidiam "affinis tristitiae", vecina de la tristeza. Esta acidia se convierte para Santo Tomás de Aquino (Summa Theologica, II, II, quaestio 35) en "delictum grave" porque se opone al amor (gaudio caritas) en sentido cristiano. Santo Tomás juzga la acediam como "species tristitiae", "tristia spiritualis boni", acercándola así a la melancolía ${ }^{30}$. Y si esta melancolía la llevamos al terreno amoroso, contamos ya

27 ¿Dónde está el lugar donde mi pensamiento repose? ¿Dónde será, dónde, que mi querer contente? Con escándalo yo busco todos los fondos y los tientos, pero no encuentro puerto donde ose detenerme. Lo que antes me guardaba de todo viento [el amor] es para mí cruel playa desierta; vagabundo voy a la casa que me es segura; trabajo es grande en la parte donde yo vagaba." (LXXVI, vV. 1-8)

¿ "La casa es una gran cuna" y también "la casa es un cuerpo de imágenes que dan al hombre razones o ilusiones de estabilidad" dice G. BAchelarl), La poética del espacio, Madrid, 1994, pp. 37 y 48 respectivamente.

20 Francesco Petrarca, Secretum, en Obras l. Prosa. Al cuidado de Francisco Rico, Madrid, 1978, p. 85.

* A fines de la Edad Media muchos escritores asocian la melancolía al planeta Saturno. Pero en realidad la conexión ya había sido estudiada por ciertos médicos árabes del siglo Xl. Existía una doctrina que atribuía a los diversos planetas las cualidades correspondientes a los temperamentos; en este caso la analogía se fundaba en la combinación de frío y sequedad, que unía la bilis negra a la naturaleza de Saturno, provocando depresión y una tendencia a la soledad y al aislamiento. Además, Saturno causaba al melancólico cierta lentitud de movimientos, pero a cambio le confería una gran inteligencia y una notable capacidad de concentración. Estas ideas se extenderán muy pronto por Europa, creando incluso una moda. Por ejemplo, en Inglaterra se llegaría a considerar la melancolía como 
con un rasgo de la "enfermedad del amor". Pero ¿qué entiende Ausiàs por amor?

El humanista Francesco Filelfo, contemporáneo de nuestro poeta, estableció que el hombre es una unidad armónica surgida de la unión de cuerpo y alma $^{31}$. Ausiàs March distinguió tres tipos de amor (LXXXVII y CXII): dos maneras extremas y una intermedia que participa en mayor o menor medida de aquéllas. La primera es el amor celestial: nada perturba la pureza amorosa del espíritu, pues el que siente el puro amor espiritual como ángel puede ir entre las gentes ("per àngel pot anar entre les gents", CXXII, 54). Su opuesto es el amor exclusivamente carnal, propio de los irracionales y de los hombres "groseros", ínfimos. El que ama únicamente la carne no alcanza el reposo, porque, satisfecho el apetito que le mueve al acto sexual, encuentra la severidad de la tristeza y, si va más allá de lo que le sacia, los rigores del enojo. Este amador se mueve entre el deseo y el hastío (fastidium), como se lee en CXXII, 57-64. El hombre perfecto se halla en este tipo de amor mixto, el que une los sentimientos de la carne y los del alma, la unidad armónica de Filelfo: "qui d'arma y cos junts ateny sentiments, / com perfect hom sent tota la sabor" (CXXII, 5556). Pero de las tres clases de amor tan sólo participa de dos, no del más alto y puro, sino del mixto:

amor a mi en delitós grau munta quant dos lligams arma y cors han a $\cdot$ strènyer... (LXXXVII, vv. 207-208)

Aunque fundamentalmente del amor rusticorum, como lo definió Andrés el Capellán:

Tant és ma carn al delit enclinada, dona no veig que.m alt, que no sospire, $i$ en posseir sens fi aquella mire de tal desig $\mathrm{m} \cdot$ arma $\cdot \mathrm{s}$ passionada; e ma raó de grat yo la perdria si.m fa esment qu- amor perdre poria.

(LXXXVII, vv. 246-250) ${ }^{32}$

enfermedad elizabethiana, y dejaría una importante huella literaria en la época isabelina, como muestra el personaje de Hamlet. En el siglo XVII, un gran melancólico escribirá un libro donde se recoge todo lo dicho sobre la melancolía desde la Antigüedad hasta sus días. Se trata de Robert Burton y de su Anatomía de la melancolía.

${ }^{31}$ En el libro III de sus Commentationes florentinae de exilio manifiesta: "Nam si hominem scimus non animum esse, non corpus, sed tertium quiddam quod et animo constet et corpore, inmortali mortalique natura, nequaquam ambigere nos oportet ita uirtutes corporis animi uirtutibus, ut corpus animo, esse subiciendum."

32 "Tanto está mi carne al deleite inclinada que no veo mujer que me contente que no suspire, y en poseer sin fin la miro, de tal deseo mi alma está apasionada y mi razón gustosamente perdería si me hace mención que amor perder podría." 
Por abrazar el amor físico, y porque además su poesía está llena de contradicciones, como su misma personalidad, Ausiàs en cierto momento dice renunciar al fin'amors para, como un fals drut, buscar los solaces y trebejos de la carne: “y de mí el fino amor se alejará rápidamente y, como falso amante, buscaré el placer" (VIII, vv. 3-4). El caso es que el poeta llega a confirmarse tanto en sus propósitos, que a menudo reniega de lo que no sea fieramente humano. De ahí que sus declaraciones rocen la blasfemia o, cuando menos, la irreverencia alguna vez, algo que entra dentro de la órbita o costumbre de los poetas provenzales y estilnovistas, para los que la amada encarnaba el sumo bien ${ }^{33}$. Un ejemplo de lo anterior nos lo suministra Ausiàs al sostener que "del Padre Santo no me hace falta tener perdón, porque mi pecado es amar locamente" (XXII, vv. 25-26), ya que su señora es su dios y su deleite ("Vós, dona, sou mon déu e mon delit", LIII, v. 25). Afirmará, igualmente sin ambages y desmintiendo lo expuesto anteriormente, que su cuerpo no es casto ("mon cors non cast", IV, 19); no obstante, le gustaría elevarse hacia el amor divino, pues asevera preferir la vida contemplativa; pero, dado que no lo consigue, le sobreviene la intransigencia de la tristeza (LXXXVII, vv. 269$270)^{34}$. Sin embargo, a despecho de todas las afirmaciones anteriores, nuestro poeta bien puede corregir su postura y entonces lo sorprendemos abominando del amor:

Vanament vols e van sós tots desigs, ..tots delits són fastigs

(IV, v. 42-43)

De modo que ya no es extraño verlo rogar a Dios, una vez más, para que le ayude a reducir las vastas fronteras de su apetito sensual, pues teme comportarse como los otros amadores, quienes "llur gros desig complit, d'amor se llexen" (LVI, v. 7), esto es, que una vez cumplido su deseo se apartan del amor. Y esta misma idea, la de que el amor finaliza y muere con la posesión física de la amada, la volverá a expresar algo más adelante (LVIII, vv. 41-44):

Lir entre carts, delits d'amor estan

partis segons dón surt la voluntat;

\footnotetext{
${ }^{33}$ Guido Guinizzelli, en el poema citado Amor, ch'al cor gentil..., manifiesto en verso del "nuevo amor", dice que, si el amante pone en peligro el destino de su alma, lo hace por culpa de la amada. Y si en el Juicio Final Dios le acusa de haber amado demasiado a su dama, no ya sólo como punto de partida para alcanzar el amor divino, el poeta alegará que, precisamente por tener la donna rostro de ángel, no puede ser falta o pecado el amarla. Una declaración muy semejante la encontramos en nuestra Celestina (Acto I), cuando Sempronio le pregunta a Calisto si es cristiano, a lo que éste responde: "¿Yo? Melibeo soy, y a Melibea adoro, y en Melibea creo, y a Melibea amo."

${ }^{34}$ Ficino, comentando el famoso poema de su amigo Cavalcanti "Donna mi priega", dice a propósito de esta composición: "[Sostiene el autor de Le rime] que estos dos amores combaten entre sí en el hombre, y aquél le rebaja a la vida bestial y voluptuosa, mientras que éste le hace elevarse a la vida angélica y contemplativa. Afirma [Cavalcanti] que éste está libre de perturbación y se encuentra en pocos; y aquél está torturado por múltiples pasiones y se apodera de la mayoría." Entre ellos de Ausiàs March. Marsil.ıo Ficino, De amore. Comentario a "El Banquete" de Platón (1469), traducción y estudio preliminar de Rocío de la Villa Ardura, Madrid, 1989, p. 191.
} 


\section{algú d'ells mor ab lo desig finat, altre delit perdurable roman ${ }^{35}$.}

Es verdad que podría seguir multiplicando ejemplos, pero no menos cierto es que, concluido el examen de las divisiones del amor y de los diversos sentimientos que ha suscitado en el ánimo del poeta, debo regresar al punto en que interrumpí la exposición para tratar de dar cuenta de lo que en siglos pretéritos se denominó la enfermedad del amor. Comencemos, pues. Platón ya había aludido en El Banquete al componente furioso del amor, pero será Aristóteles el primero que dé forma científica a la doctrina que concibe el amor como enfermedad. Aristóteles segmenta las perturbaciones causadas por el amor en dos grupos, las mentales y las somáticas, y a continuación identifica el amor como el deseo de reproducción. Esta apetencia, arguye, provoca una sobreabundancia de sangre en el corazón, que se extenderá por todo el cuerpo, excitando así los impulsos libidinosos. Este ardor, que repudia el sosiego y que por eso mismo puede convertirse en una fiebre continua de la sangre, impulsa al amante a reclamar insistentemente el objeto de su pasión. Pero para que surja este apetito debe precederlo una imagen bella que excite la vista (Ética a Nicómaco, IX.5.1166 AE - $1167 \mathrm{AC}$ ), ya que nada hay en el entendimiento que no haya estado antes en los sentidos (Sobre el alma, III, 12). Esta opinión la recogerá Ausiàs March:

Lo gest dels ulls e de aquells la forma fet han en mi passió molt estranya

(CXVI, vv. 121-122) $)^{36}$

Y a propósito del sentido de la vista, por el cual ya sabemos que entra el amor en el alma, Aristóteles (De insomnis, II, 459) escribe que las mujeres, durante la menstruación, a menudo manchan de sangre el espejo en el que se miran. Dichas gotitas de sangre recibieron el nombre de spiriti, partículas sutilísimas de sangre que salen de los ojos. Esta teoría, la de los spiriti, la sistematizará Alberto Magno, la retomará Arnau de Vilanova, y poéticamente la encontraremos en Cavalcanti ("Deh, spiriti miei, quando mi vedete") y en los vv. 51-54 de la canción "Donne ch'avete intelletto d'amore" de la Vita nuova

\footnotetext{
${ }^{35}$ Estos versos recuerdan aquellos del Libro de Buen Amor: "Esto dijo doña Endrina: / Es una cosa probada / que por sus besos la dueña resulta siempre engañada: / pone en gran encendimiento el abrazar a la amada / toda mujer es vencida si esta recompensa es dada." Edición modernizada, estudio y notas de N. Salvador Miguel, Madrid, 1985, p. 155. Y en un contexto distinto, filosófico, dice Marsilio Ficino: "El deseo de tocar no es parte del amor ni afecto del amante, sino una especie de petulancia, y una perturbación propia de un esclavo (De amore, ed. cit. p. 47). Este concepto llega hasta Cervantes: "Si [el amante] alcanza lo que desea, mengua el deseo con la posesión de la cosa deseada. y quizá abriéndose entonces los ojos del entendimiento, se ve ser bien que se aborrezca lo que antes se adoraba." (La gitanilla, edición de H. Sieber, Madrid, 1992, p. 85)

36 "El gesto de los ojos y de ellos la forma han hecho en mí pasión muy extraña." Aquí gesto debe entenderse como "imagen", al igual que en el soneto de Garcilaso: "Scrito está en mi alma vuestro gesto". León Hebreo en el ya lejano 1535 aún repite la misma idea de Aristóteles: “...si tu espléndida belleza no hubiese penetrado por mis ojos, no habría podido herir tanto como lo hizo los sentidos y la fantasía", Diálogos de amor, introducción y notas de Andrés Soria Olmedo, Madrid, 1986, p. 193.
} 
de Dante, proyectándose luego al Renacimiento italiano y español como lugar común (véase, por ejemplo, el soneto de Giovanni Guidiccione, "Fiamma gentil, che da begli occhi muovi"; el de Garcilaso, "De aquella vista pura y excelente", o el de Francisco de Figueroa, "Partiendo de la luz, donde solía") y al Barroco, aunque ahora adopte un tono burlón o desmitificador, como se advierte en el soneto lopesco "Espíritus sanguíneos vaporosos", perteneciente a las Rimas de Tomé de Burguillos, y que enlaza con una tradición antipetrarquista encarnada en las figuras renacentistas de Diego Hurtado de Mendoza o de Baltasar de Alcázar. Sin embargo, cuando la medicina avanza y la teoría de los spiriti parece olvidada por los escritores y poetas, encontramos que Juan Valera recurre a ella para explicar el enamoramiento del joven don Luis de Vargas en Pepita Jiménez:

Cada vez que se encuentran nuestras miradas se lanzan en ellas nuestras almas, y en los rayos que se cruzan se me figura que se unen y se compenetran. Allí se descubren mil inefables misterios de amor, allí se comunican sentimientos que por otro medio no llegarían a saberse, y se recitan poesías que no caben en lengua humana, y se cantan canciones que no hay voz que exprese ni acordada cítara que module ${ }^{37}$.

Los spiriti se originan en el corazón por el calor de los alimentos y aquéllos, al ser muy ligeros, fácilmente ascienden a las partes más elevadas del cuerpo: los ojos, de donde parten hacia los de la amada. Que el rayo lanzado por los ojos lleve consigo el vapor seco de los spiriti, y con éste la sangre, se explica porque los ojos enfermos y rojos comunican la misma enfermedad a los de quien los mira, pues le trasladan la sangre corrupta. De este modo los spiriti del amante, enfermos de amor, le contagian la misma enfermedad a la persona amada, ya que los spiriti pasan de los ojos al corazón, y de ahí se extienden a todo el organismo. Por eso nadie debe asombrarse, argumentaban, si oye que el amante ha concebido en su mente una imagen o figura de la amada, pues el pensar en ella conmueve los spiriti interiores y pinta en ellos la imagen de la cosa pensada. Éstos agitan la sangre y reproducen la imagen del objeto amado ${ }^{38}$.

Así, pues, la contemplación de una forma bella altera la temperatura del cuerpo por medio de los spiriti del corazón, rompiendo no sólo el equilibrio fisiológico, sino también el psicológico. La imagen de esta forma camina desde la vista al entendimiento, atravesando primeramente la memoria y la imaginación, y la enfermedad surge tan sólo cuando el continuo pensar en la amada y en el afán de poseerla degeneran en obsesión. Ausiàs ilustra este proceso:

37 JuAN VALERA, op. cit, edición de Leonardo Romero, Madrid, 1992, p. 250.

${ }^{37}$ Fernando de Herrera expresará en sus Anotaciones: “...mas las imágenes de los que aman, esculpidas en ella [en el alma] como inustiones hechas a fuego, dejan impresas en la memoria formas que se mueven y viven y hablan y permanecen en otro tiempo.", ed. de Gallego Morell, Madrid, 1972, p. 336. Anteriormente. Santo Tomás había tratado del dolor y el hastío que provoca la memoria: "...memoria delectationes non causat in eo delectationem, sed fastidium", Summa Theologica, III, 33, 2. 
Aquest- amor per nostres senys nos entra

e fa present al comú seny, e passa

lo presentat, per sos migs, al entendre,

d'on voler creix tan como l'hom s'hi delita.

(XLV, vv. 33-36)

Un par de siglos después, Lucrecio, haciéndose acompañar por el materialismo epicúreo en sus teorías, reduce el amor a un mero estímulo físico: "Se excita en nosotros aquel semen de que antes hablábamos tan pronto la edad viril robustece los miembros. Pues cada ser es conmovido por una causa distinta, y al semen de un hombre sólo le excita la influencia de una persona humana. Expulsado apenas de las partes donde tiene su sede, el semen se retira del resto del cuerpo y, atravesando miembros y órganos, concéntrase en una determinada región de los nervios y excita al momento las partes genitales del cuerpo. Irritadas éstas, se hinchan de semen, y surge el anhelo de expulsarlo hacia el objeto del violento deseo, de modo que el cuerpo busca el cuerpo que le ha herido el alma de amor" 39 . El remedio que ofrece consistirá en mantener relaciones sexuales con la persona que es objeto de deseo. "Pues aunque el ser amado esté ausente, a mano están sus imágenes, y su dulce nombre resuena en nuestros oídos." Lo mismo ocurre en Ausiàs (L, vv. 9-10):

En vos penssant ma penssa és enciosa dompda's per vos, ma voluntat no.s farta ${ }^{40}$

Prosigue Lucrecio:

Pero conviene huir de tales imágenes, evitar lo que dé pábulo al amor y volver la mente a otras ideas: descargar el humor acumulado contra un cuerpo cualquiera, antes que retenerlo y guardarlo para un único amor, y procurarse así cuitas e inevitable dolor.

Justo lo que no hará el valenciano, al menos de camisa para afuera:

no desig toch de ningun. altre mujer

(CXVI, v. 96).

Esta doctrina del amor como enfermedad la heredan los Padres de la Iglesia, quienes se inspiran en Platón y en los estoicos en su concepción filosófica, mientras que la fisiológica la toman de Hipócrates y Galeno. Apoyándose en ambas tradiciones, precisan que el amor es un impulso sensible que comporta

\footnotetext{
${ }^{34}$ Lucrecto, De rerum natura, IV, citado por Martín de Riquer y J. M. Valverde, Historia de la literatura universal, v. I, Barcelona, 1984, p. 312 y 313.

4" Castelvetro, comentando el soneto XCIV de Petrarca ("Quando giunge per gli occhi al cor profondo"), de contenido parecido al fragmento de Ausiàs, dice: "Quando un amante riceve per gli occhi nel cuore l'immagine della persona amata, l'anima si parte del corpo e va nel corpo della persona amata. Dove se è riceuto, vive nell' amata persona e moure in sè”, Cfr. L. BALDACCI, Il petrarquismo italiano nel Cinquecento, Milán-Nápoles, 1957, p. 55.
} 
una alteración en el organismo que podría ser permanente. A causa de esta alteración, insisten en que la pasión amorosa aparta al hombre del camino de la razón y la virtud, idea familiar en Ausiàs March, si se recuerda, pues el hombre, especifica Clemente de Alejandría, está compuesto de:

anima e corpo, e il corpo è la sede e i veicolo dell'anima. In quanto composto di anima y corpo, l'uomo consiste di una parte razionale e di otra irrazionale. L'anima razionale vivifice il corpo, e per mezzo dello spirito vitale costituise il principio della sua constituzione animale ${ }^{41}$.

Por tanto, el alma racional debe dominar a la parte irascible y la concupiscible. Por efecto del pecado original el alma racional ha perdido el control, y las pasiones, que están sometidas al poder del demonio, perturban el alma, a menos que la socorra la gracia de Dios. El amor, pues, es considerado como una especie de enfermedad tanto del espíritu como del cuerpo, y en consecuencia habrá de ser combatido con todos los medios, a fin de restituir el equilibrio inicial entre ambos, sin el cual nadie puede acceder a la Gloria.

Santa Ildegarda, discutiendo sobre el humor melancholicus (tráigase a la mente lo dicho sobre la tristeza de Ausiàs March), afirma que es una desviación del estado perfecto que el hombre tenía en el Paraíso, y en su opúsculo Causae et Curae remonta la enfermedad al pecado original, pues cuando Adán fue expulsado del Edén, el hombre heredó esta dolencia, la melancolía, que por provenir del demonio es incurable. De esta visión trágica de vida se desprende que la melancolía, y con ella las demás pasiones, son una enfermedad común a todos los hombres y que tan sólo el religioso puede aliviarlas.

Habrá que esperar a los médicos árabes para ver cómo evoluciona el concepto de amor como enfermedad, haciendo equivocarse a personalidades tan ilustres como Menéndez Pelayo, quien consideró a Ausiàs March un romántico anticipado, cuando en realidad lo único que hizo el valenciano fue aplicar las teorías médicas árabes a su poesía. Me estoy refiriendo a la escena del cementerio, a donde acude Ausiàs en busca del amparo de los sepulcros:

$$
\begin{aligned}
& \text { e vaja yo los sepulcres cercant, } \\
& \text { interrogant ànimes infernades, } \\
& \text { e respondran, car no són companyades } \\
& \text { d'altre que mi en son contínuu plant. } \\
& \text { (XIII, vv. } 5-8)^{42}
\end{aligned}
$$

"Y como cada cual busca su semejante", dice el poeta a continuación, haciéndose eco de aquella afirmación plotiniana, "por eso no me place el trato

\footnotetext{
${ }^{41}$ Massimo Clavolella, La "malattia d'amore" dall'Antichità al Medioevo, Roma, 1976, p. 32.

42 "Y vaya yo buscando los sepulcros, interrogando almas infernales que me contestarán, ya que no están acompañadas de otro sino de mí en su continuo llanto".
} 
con los vivos", pues además "esquivan imaginar mi estado" y huyen de él "como de un muerto". Ausiàs concluye reconociendo su enfermedad, una enfermedad que no podrá sanar ningún médico ("de mon desig no·m porá quarir metge", v.16): la temible licantropía.

Razes (850-923 ó 932), en su Liber Continens, identifica la enfermedad del amor con la más aguda melancolía: la licantropía, una especie de locura que hace al hombre comportarse como un lobo. El amor se convierte en algo trágico, pues la única escapatoria es la muerte. Sostiene Razes que, antes de sobrevenir ésta, el amante cobra apariencia de lobo, evita a la gente, se esconde y, por la noche, vaga por los cementerios, como hace nuestro poeta. Se advierte así que no es necesario atribuir costumbres románticas a Ausiàs, ya que pese a su indudable genialidad no deja de ser un hombre del siglo XV, y el Romanticismo aún le queda un poco lejos.

En lo atingente a la medicina árabe, aún faltarían por examinar las teorías de Ali Abbas, Abulcasim y Avicena, que reclamarían más páginas de las permitidas en este trabajo. Por eso he decidido centrarme en los postulados de un coterráneo de nuestro poeta, Arnau de Vilanova, médico del siglo XIII, cuyo estudio sobre la enfermedad del amor puede arrojar luz sobre el tema que nos ocupa. De entrada he de consignar que Arnau de Vilanova fue el primer médico que escribió un tratado sobre el amor, De amore qui heroicus nominatur ("Sobre el amor denominado heroico"), donde concilia la tradición médica árabe y la filosofía antigua. A diferencia de los filósofos y médicos anteriores, Vilanova no considera el amor como una enfermedad propia y auténtica, sino como un fuerte deseo que podía conducir al estado patológico. Distingue en el amor dos momentos: el pasional y el patológico, que no están ligados necesariamente. Así, si la enfermedad surge solamente del deseo, éste no desemboca irremediablemente en enfermedad. El amor es un deseo que nace cuando el hombre tiene una sobreabundancia de humores y de sangre, cuando el organismo se halla en una condición cálida y húmeda. Esta sobreabundancia de sangre es la que origina el semen, que es el responsable del amor entre hombre y mujer, aunque también un exceso de humores melancólicos genera este irreprimible deseo sensual. De modo que tanto el semen como el humor melancólico deben ser expulsados del organismo para evitar sucumbir a la enfermedad. No obstante, estas causas fisiológicas, que fomentaban o favorecían la pasión amorosa, Vilanova las relega ante una causa principal, que era extrínseca: la vista, tal como habían estipulado Aristóteles y Abulcasim, entre otros muchos. Pero Vilanova parte de este presupuesto para desarrollarlo de un modo más puntual:

...amor...qui dicitur hereos, est vehemens et assidua cogitatio supra rem desideratum cum confidentia obtinendi delectabile apprehensum ex ea. Huius autem notificationis veritas sic monstratur: primo namque copia praesentatur alicui, seu deuenit ad apprehensum eiusdem vel per se, vel per resolutionem alterius, vel per simulacrum aliquod, vel quomodolibet aliter, et ex forma dictae rei, vel accidentibus eius, 
apprehendens, aliquod concipit delectabile, sicut ex rebus omnibus, ex gratae speciei intuitu, aut in homine ex suauitate colloquii, aut liberalitate personae seu consuetudinis lenocinio, seu circums tantiis quibuscunque... ${ }^{43}$

Este fuerte deseo es de naturaleza sensual y no ha adquirido aún el carácter morboso que distingue el estado patológico, pues si el sujeto logra poseer el objeto amado, su ansiedad desaparece, recuperando así el equilibrio del organismo. Ahora bien, si los impulsos de los sentidos no son satisfechos (cum confidentia obtinendi delectabile apprehensum), las consecuencias de esta carencia pueden ser fatales: el pensar continuamente en el objeto de deseo va a degenerar en una idea obsesiva que paralizará toda la actividad cognoscitiva del sujeto. Ausiàs lo expresa de este modo:

Dormint, vetlant, yo tinch la fantasia en contemplar qui am, qui és, què val, e quant més trob, llavors me va pus mal pel pensament qui-m met en gran follia, hoc e.n tan gran que yo am son desdeny, son poch parlar, son estat tal qual és, més qu- ésser rey del poble tot francès ¡e muyra prest si mon parlar yo.m feny! (CI, vv. 33-40) $)^{44}$

Y también:

En vós penssant ma penssa és enclosa, dompda's per vós, ma voluntat no.s farta.

$$
(\mathrm{L}, \text { vv. } 9-10)^{45}
$$

Este pensamiento constante en la amada contribuye a que el sujeto anteponga la satisfacción de sus propios instintos sensuales, según explica Vilanova, a cualquier otra actividad ${ }^{46}$. Así lo vemos en nuestro poeta:

${ }^{4.3}$ De amore qui heroicus nominatur, citado por MAssino CIAvolliLA, Op. cit., pp. $70-71$

+4 "Durmiendo, velando, la fantasía tengo contemplando a quien amo, qué es, qué vale y cuanto más hallo entonces más mal me va al pensamiento, pues me pone en gran locura, sí, y tan grande que quiero su desdén, su poco hablar, su condición tal cual es. más que ser rey de todo el pueblo francés. ¡Y presto muera yo si finjo en mi hablar!"

45 "Pensando en vos está encerrado mi pensamiento, dominado está por vos, mi voluntad no se harta", proclama Ausiàs March. Y también en LXXVIII, v. 17: "Mon pensament és en vós més qu.en mi”, mi pensamiento está más en vos que en mí. Unos años más tarde, en el diálogo neoplatónico entre Sofía y Filón, éste le dice: "Te diré que mi mente ocupada en contemplar, como de costumbre, la belleza en ti contenida, grabada en imagen en ella y siempre deseada, me ha hecho abandonar los sentidos externos.", Lé́n Hebreo. Diálogos de amor, introducción y notas de Andrés Soria Olmedo, Madrid. 1986, p. 192.

46. "Hic autem amor furiosus, cum particulare rei exemplo lucidius pateat inter virum et mulierem, videtur imperio subjugato rationis incendi, propter singularem coytus delectatiomem.", Arnau de Vilanova, De amore qui heroicus nominatur, citado por Massimo Ciavolella, Op. cit., p. 75. 
Aquella carn on lo meu espirit entrar volgué abans quen Paradís. $(X C I X, \text { vv. } 25-27)^{47}$

En consecuencia, la razón enferma y conduce al hombre a juzgar erróneamente, pues sólo anhela conseguir el objeto de deseo como si fuera el único bien. Aparecen los síntomas de la enfermedad del amor: rostro demacrado, ojos hundidos a causa de que el organismo ya no es capaz de compensar el aumento de los humores secos, pérdida del apetito, insomnio e incremento del humor melancólico ${ }^{48}$. Pero a pesar de esta sequedad, puede suceder que, cuando el amante se acuerda de la amada, comience a llorar abundantemente. Tal estado de abatimiento y tristeza es susceptible, sin embargo, de tornarse rápidamente en euforia: el equivalente a lo que los psiquiatras modernos denominan psicosis maniaco-depresiva. Estas bruscas alteraciones del humor, explica Vilanova, van acompañados de un súbito cambio de color de cara: pálido primero y bermejo después, debido al ascenso de temperatura motivado por los momentos de desesperación amorosa. Al igual que Razes, el médico valenciano habla de la licantropía como un estado altamente peligroso. Para remediarlo y hacer que el sujeto recobre la razón, Vilanova cifra sus esperanzas en una terapia consistente en hacer que el enfermo distraiga en lo posible su atención del objeto amado, o en intentar convertir su amor en odio. Prescribe, además, una dieta ligera, descanso y baños frecuentes para expulsar del organismo los humores nocivos, según solían hacer en aquella época en los manicomios. Por otro lado, se recomendaba también la unión sexual con cualquier doncella joven a fin de mitigar el deseo de poseer a la amada, causante de todos los desarreglos ${ }^{49}$. Pero esto último, nos advierte Vilanova, exige moderación, ya que las relaciones sexuales continuadas provocan delgadez extrema y desecan el organismo.

A modo de conclusión, diremos que si la teoría de la enfermedad del amor en sus orígenes dependía estrechamente del concepto de melancolía y de locura, abandona con Arnau de Vilanova su papel de dependencia para convertirse en agente causal de aquéllas. Fueron éstas, la melancolía y la locura, las que atenazaron a Ausiàs March, a un hombre genial y altanero que, como maestro de amor, aspiró a vivir y a morir en él.

\footnotetext{
47 "Aquella carne donde mi espíritu entrar deseó antes que en el Paraíso".

48 "El poco dormir me trae magrez al cuerpo" (II, v. 37), dice nuestro poeta. Pero también se lamenta de que "tanto desear con desesperación consume al hombre" (XXI, vv. 11-12). Y refiriéndose a la antigua teoría de los humores, leemos: "Dentro del cuerpo del hombre los humores se revuelven, de tiempo en tiempo su poder se trasmuda: en un solo día reina melancolía, y aquel mismo cólera, sangre y flema" (XCIV, vv. 17-20)

${ }^{49}$ Constantino Africano (Liber de Coitu, Opera, vol. I, p. 303) había hecho ya la misma recomendación: "Coitus solvit malum habitum corporis, et furorem mitigat. Prodest melancholicis et amens revocat ad notitiam, et solvit amorem concupiscentis, licet concumbat cum alia quam cuncupivit".
} 